\title{
LOS DESAFÍOS DEL DERECHO DE FAMILIA EN EL SIGLO XXI \\ (Ensayo)
}

\author{
RAMIRO DE VALDIVIA CANO*
}

\begin{abstract}
Resumen
El matrimonio y la familia son institutos naturales y fundamentales constantemente erosionados y amenazados de disolución debido a la dación de normas positivas que facilitan el divorcio por causales, en esencia, anticonstitucionales. En el presente ensayo se interpreta, a la luz del Derecho Natural, el Derecho Internacional y la doctrina católica, la problemática legal y social derivada de los constantes embates a la familia y el matrimonio por parte de la comunidad política. Asimismo, hace un llamado a la búsqueda de instrumentos de protección de la dignidad y libertad del hombre, ante la prepotencia de las fuerzas sociales y las potenciales arbitrariedades del poder. Establece la necesidad de conferir un carácter institucional al matrimonio, fundándolo sobre un acto público, social y jurídicamente reconocido; y, propugna que la responsabilidad en el cuidado y la promoción de la familia, compete principalmente a toda la sociedad.
\end{abstract}

Palabras clave: Familia - Matrimonio - Divorcio - Doctrina católica Derechos de la familia - Amor conyugal - Política familiar - Control de convencionalidad - Independencia del Poder Judicial.

\begin{abstract}
Marriage and family are natural and fundamental institutions that are constantly being eroded and threatened to be dissolved due to the enactment of positive norms that facilitate at-fault divorce which are, in essence, anticonstitutional. In the light of Natural Law, International Law and the Catholic Scholar doctrine, this essay interprets the legal and social problems derived from the constant attacks on family and marriage by the political community. Furthermore, it beckons the search for instruments protective of man's dignity and freedom, in the face of the arrogance of the social forces and the potential arbitrarities of power. It also establishes the need to confer an institutional character to marriage, basing it on a public, social and legally recognized act; and proposes that society as a whole, is responsible for the care and promotion of the family.
\end{abstract}

Key words: Family - Marriage - Divorce - Catholic Scholar Doctrine Family Rights - Spousal Love - Family Policy - Control of Conventionality - Autonomy of the Judiciary.

\section{Sumario}

1. Introducción. 2. La Superstición del divorcio. 3. Política familiar. 4. Hoja de ruta. 5. Colofón.

\footnotetext{
" Juez Supremo Titular de la Corte Suprema de Justicia de la República-Poder Judicial del Perú.
} 


\section{INTRODUCCIÓN}

La defensa de la dignidad del hombre, la familia y el matrimonio es un inmenso ámbito de reflexión y de acción social, educativa y política. Aún si se limita al campo jurídico, se tiene que compulsar el fracaso del control de la constitucionalidad de las leyes que norman la familia que es la célula básica de la sociedad -o que lo fue, desde tiempos inmemoriales. Por cierto, entre los muchos defectos de la Constitución de 1993, sobresale la incoherencia con que trata a la familia y el matrimonio. En su Art. $4^{\circ}$ (Protección a la familia. Promoción del matrimonio) reconoce la obligación del Estado de proteger la familia y promover el matrimonio. "Reconoce a estos últimos como institutos naturales y fundamentales de la sociedad." Pero, a renglón seguido, establece que esta misma norma puede ser modificada y arrasada al gusto electorero de cualquier mayoría simple del Congreso. ¡Sin necesidad de seguir el trámite obligatorio de modificación o de enmienda constitucional exigido para cualquiera de las otras normas constitucionales! ${ }^{1}$.

Por otro lado, teniendo en cuenta las fuentes iusnaturalistas de los arts. $1^{\circ}, 2^{\circ}$ y $4^{\circ}$ y Cuarta Disposición Final y Transitoria de la Constitución Política del Perú; y las concordantes normas contenidas en la Convención Interamericana sobre Derechos Humanos y el Pacto Internacional de Derechos Económicos, Sociales y Culturales, es necesario hacer una advertencia: los jueces que están llamados a activar el control de la convencionalidad en el área del Derecho Familiar, deberán tener en cuenta que se puede sostener que competiría al Estado social y democrático de Derecho regular los efectos civiles del matrimonio. Pero, ni el Estado ni la sociedad deben soslayar su dignidad en sus características específicas, que exigen ser salvaguardadas frente a cualquier pretensión de alteración de su naturaleza. La sociedad no puede disponer del vínculo matrimonial, con el cual los dos esposos se prometen fidelidad, asistencia recíproca y apertura a los hijos.

Pero estas pretensiones son insistentes y la meta de erosión de la naturaleza del matrimonio quedó institucionalizada en la sociedad cuando el legislador comenzó a hacer concesiones demagógicas ante las presiones políticas. No otro es el origen del decreto ley de 8 de octubre de 1930 que estableció el divorcio vincular en el Perú. Ahora, ya se llega al extremo de justificar crímenes contra la vida, la libertad y la dignidad humanas so pretexto de ejercicio de la libertad en el ámbito familiar. Se pretende reconocer validez jurídica a tales extremos de

1 Consultar Rubio CORREA, Marcial. «Título VI.- Reforma de la Constitución». En: Para Conocer la Constitución Política del Perú de 1993. Lima: Fondo Editorial PUCP, pp. 311 y ss. 
la prepotencia solo porque se enfundan en las fanfarrias de las formalidades de la norma ordinaria legal o constitucional. $\mathrm{O}$ en interpretaciones incorrectas de lo que es libertad y de lo que es Derecho Positivo. No obstante, la Constitución histórica del Perú no puede menos que reconocer el fundamento antropológico de la familia y así lo hace la vigente cuando señala que "la defensa de la persona humana y el respeto de su dignidad son el fin supremo de la sociedad y del Estado" (art. $1^{\circ}$ ). Y a la familia y al matrimonio como "institutos naturales y fundamentales de la sociedad". Pero, no menos lírica ha resultado la que define el matrimonio. (Art. $\left.4^{\circ}\right)^{2}$.

Ahora bien, aplicando la cuestión al Derecho de Familia, cabe preguntarse con Benedicto XVI, ¿Cómo podemos reconocer lo que es justo? ¿Cómo podemos distinguir entre el bien y el mal, entre el derecho verdadero y el derecho solo aparente $?^{3}$ La cuestión es decisiva y ante ella se encuentra también el político y la política misma.

Para regular una parte materia del Derecho de Familia que se ha de regular jurídicamente, el criterio de la mayoría puede ser un criterio suficiente. Pero es evidente que en las cuestiones fundamentales del Derecho, en las cuales está en juego la dignidad del hombre y de la humanidad, el principio de la mayoría de votos no basta: En el proceso de formación del Derecho, una persona responsable debe buscar los criterios pertinentes de su orientación. En el siglo III, el gran teólogo Orígenes, citado por Benedicto XV, justificó así la resistencia de los cristianos a determinados ordenamientos jurídicos en vigor: "Si uno se encontrara entre los escitas, cuyas leyes van contra la ley divina, y se viera obligado a vivir entre ellos..., con razón formaría por amor a la verdad -que, para los escitas, es ilegalidad-alianza con quienes sintieran como él contra lo que aquellos tienen por ley..."4

Aquello que se atribuye a una entidad por algún título recibe el nombre de ius (derecho), en mérito de una cualidad que la sitúa en el mundo jurídico. Aquello le es debido en sentido estricto. Entre lo que es debido al matrimonio, y que el Estado y la sociedad deben reconocerle se encuentra:

\footnotetext{
2 Constitución Política del Perú

Artículo $4^{\circ}$. La comunidad y el Estado protegen especialmente al niño, al adolescente, a la madre y al anciano en situación de abandono. También protegen a la familia y promueven el matrimonio. Reconocen a estos últimos como institutos naturales y fundamentales de la sociedad.

La forma del matrimonio y las causas de separación y de disolución son reguladas por la ley." Ver: Rubio Correa, Marcial. Para Conocer la Constitución Política del Perú de 1993. Segunda edición. Lima: Fondo Editorial PUCP, 2010, p. 54.

3 http://www.romereports.com/palio/discurso-de-benedicto-xvi-en-el-parlamento-aleman-comoreconocer-que-es-justo-y-que-es-injusto-spanish-4955.html\#.TnuXWBMJNzY.facebook. Consultado: 01 de noviembre del 2011, 16:37 horas.

4 BENEDICTO XVI. Op. cit.
} 
- La totalidad, en razón de la cual los cónyuges se entregan recíprocamente en todos los aspectos de la persona -físicos y espirituales-;

- La unidad que los hace " una sola carne»;

- La indisolubilidad;

- La fidelidad que exige la donación recíproca y definitiva;

- La fecundidad a la que naturalmente está abierto. El desprecio de este rasgo que el mundo actual detenta ya está dando, como producto más ostensible, el envejecimiento poblacional con gravísimas consecuencias sociales y económicas, para mencionar solo lo estadísticamente obvio.

- El designio sobre el matrimonio - designio accesible a la razón humana, no obstante las dificultades debidas al egoísmo - no puede ser juzgado exclusivamente a la luz de los comportamientos de hecho y de las situaciones concretas que se alejan de él. La poligamia es una negación radical de su designio original, «porque es contraria a la igual dignidad personal del varón y de la mujer, que en el matrimonio se dan con un amor total y por lo mismo único y exclusivo».

El matrimonio, en su verdad «objetiva», está ordenado a la procreación y educación de los hijos. La unión matrimonial, en efecto, permite vivir en plenitud el don sincero de sí mismo, cuyo fruto son los hijos que, a su vez, son un don para los padres, para la entera familia y para toda la sociedad.

El matrimonio, sin embargo, no ha sido instituido únicamente en orden a la procreación: su carácter indisoluble y su valor de comunión permanecen incluso en la infertilidad matrimonial. También existen las alternativas de la adopción y el voluntariado en el ejercicio de servicios altruistas.

Pese a todo, un sector de la comunidad política pretende ignorar que la cuestión de las justas relaciones derivadas del matrimonio y la familia tiene sus raíces y sus respuestas en la esencia del ser humano. Allí se encuentra el lazo indisoluble entre espíritu y cuerpo. De esa pretendida ignorancia brotan las políticas dirigidas a banalizar la familia, el matrimonio, la vida humana y la sexualidad -pese a la existencia de normas que reconocen a la familia como elemento natural y fundamental de la sociedad-.

Cuando la comunidad política banaliza las relaciones familiares deja de lado que la totalidad del hombre incluye la dimensión del tiempo; que el «sí» matrimonial significa «sí, para siempre», y que es irrevocable ya que está destinado al don de nuevas vidas. La libertad del «sí» es la libertad capaz de asumir lo que es definitivo; no se limita a la búsqueda del placer circunstancial legítimo o no. 
El matrimonio, como institución, no es, por tanto, una franquicia o una injerencia indebida de la sociedad o del Estado, ni es una concesión de la Constitución o del Código Civil; ni del convenio internacional -tampoco es una imposición desde el exterior en la realidad más privada de cada vida. Por el contrario, es una exigencia intrínseca del pacto de amor conyugal y de la profundidad de la persona humana.

Todo lo cual hace repugnante, desde el punto de vista jurídico la violenta contradicción en que se incurre en el mismo art. $4^{\circ}$ de la Constitución al poner en manos de cualquier mayoría -parlamentaria- simple el destino de estos "institutos naturales y fundamentales." Más aún, al otorgar a esos grupos de políticos desorbitadas facultades para regular causas de demolición de las familias y de disolución del matrimonio. Nótese que, en todos los demás casos, la enmienda más menuda y timorata del texto constitucional requiere de un intrincado y muy oneroso proceso nacional de modificación. El uso que los políticos dan a tales facultades desorbitadas queda plasmado en aquellas leyes que posibilitan el divorcio fundando la demanda en hecho propio del cónyuge divorcista; en las leyes que cercenan la unidad y exclusividad de la función jurisdiccional para entregarla, cuando se trata de demandas de divorcio, a no-siempre-doctos alcaldes y notarios ${ }^{5}$.

Pero, la agonía apenas comienza y ¡ay! el cadáver sigue muriendo; y "se extiende la herida del divorcio y de las uniones libres" ${ }^{\prime \prime}$.

Es por esta vía que la sociedad peruana del s. XXI padece de diferentes causales y procedimientos "legales" -y anticonstitucionales en esencia- de disolución: el divorcio y el divorcio frívolo. Éstas son expresiones de una falsa libertad o de una libertad anárquica que se presenta erróneamente como auténtica liberación del hombre: la superstición del divorcio. Padece también de institutos "legales", supuestamente sucedáneos y paralelos al matrimonio y a la familia. Algunos de ellos, cobijados en la "libertad" que ululan los arts. $5^{\circ}$ y $6^{\circ}$ de la Constitución -que son incompatibles con los antes mencionados arts. $1^{\circ}$ y $4^{\circ}$. En el divorcio frívolo, la pseudo-libertad se basa en proyectos de demolición del cuerpo y de la dignidad del hombre, del amor y de la familia. Su presupuesto es que el político puede imponer sus criterios demagógicos o no; y que el hombre puede hacer de sí y de su

5 Ver Ley $N^{\circ} 27495$ de 7 de julio del 2001, denominada "Ley que incorpora la separación de hecho como causal de separación de cuerpos y posterior divorcio". También la Ley N²29227, denominada "Ley que regula el procedimiento no contencioso de la separación convencional y divorcio ulterior en las municipalidades y notarías" de 16 de mayo del 2008.

6 Así lo denunció Benedicto XVI su visita a Brasil (Mayo, 2007). 
familia lo que quiera cuando se trata de alcanzar sus propias propuestas hedonísticas o egoístas. ${ }^{7}$

Esta libertad irresponsable (que, en consecuencia, no es libertad) deviene en un dualismo que desconoce el auténtico ser y la dignidad de la persona; y en un envilecimiento del amor humano. Reduce la naturaleza humana a un conjunto de funciones fisiológicas, ajenas a la dignidad humana, de las que se puede disponer según los propios gustos, en la medida del propio poder económico o político, y con el activismo de los políticos que responden a exigencias partidaristas coyunturales.

Las normas peruanas anti-familia atacan la dignidad humana, al no reconocer ni a la familia ni al matrimonio como definitivos y definitorios, y al promover aquellas políticas que consideran que el hombre tiene como medida última el propio ego con sus caprichos y poder -pese a revestirse de la apariencia de libertad-. Es esta una situación semejante a la descrita por el Papa Benedicto XVI refiriéndose a los magistrados y abogados anti-nazis de la resistencia alemana: "Para ellos era evidente, de modo irrefutable, que el derecho vigente era en realidad una injusticia. Pero en las decisiones de un político democrático no es tan evidente la cuestión sobre lo que ahora corresponde a la ley de la verdad, lo que es verdaderamente justo y puede transformarse en ley. Hoy no es de modo alguno evidente de por sí lo que es justo respecto a las cuestiones antropológicas fundamentales y pueda convertirse en derecho vigente. A la pregunta de cómo se puede reconocer lo que es verdaderamente justo, y servir así a la justicia en la legislación, nunca ha sido fácil encontrar la respuesta y hoy, con la abundancia de nuestros conocimientos y de nuestras capacidades, dicha cuestión se ha hecho todavía más difícil"8.

Como corolario de este ensayo se hace la propuesta, a magistrados y abogados, de defender la familia y el matrimonio según las definiciones que de esas instituciones hace el Art. $4^{\circ}$ de la Constitución y aún asumir el rol de combatientes de la resistencia a la norma injusta o arbitraria en los mismos términos propuestos por el Art. $7^{\circ}$ de la Constitución Política, el cual reconoce que "Todos tienen derecho a la protección de su salud, la del medio familiar y la de la comunidad así como el deber de contribuir a su

\footnotetext{
7 Véase la Ley $N^{\circ} 29227$ de 16 de mayo del 2008, Ley que regula el procedimiento no contencioso de la separación convencional y divorcio ulterior en las municipalidades y notarías, y su reglamento, aprobado por Decreto Supremo No 009-2008- JUS.

8 http://www.romereports.com/palio/discurso-de-benedicto-xvi-en-el-parlamento-aleman-comoreconocer -que-es-justo-y-que-es-injusto-spanish-4955.html\#.TnuXWBMJNzY.facebook.
} 
promoción y defensa". Nótese que en este dispositivo la Constitución ha de referirse al concepto integral de salud; puesto que el art. $11^{\circ}$ se refiere a las prestaciones de salud física. Esa sería su contribución al servicio al derecho y a toda la humanidad.

\section{LA SUPERSTICIÓN DEL DIVORCIO}

Barbara Dafoe Whitehead, en su obra La cultura del divorcio, se refiere a la profunda admiración que los lectores de los más diversos países manifiestan desde inicios del s. XX, por la manera en la que G. K. Chesterton supo escribir sobre el matrimonio y sobre el divorcio; y señala cómo, a esta última institución, el escritor inglés califica de superstición y al matrimonio como la realidad espléndida de la condición humana. Pues bien, una vez desmitologizado el divorcio como elemento maligno que es, aparece la verdadera esencia del matrimonio, como algo difícil, heroico, profundamente humano y como escuela de humanidad y de libertad.

Justamente, en el presente ensayo se tratará de aquello que el genial humanista católico Gilbert Keith Chesterton denomina La superstición del divorcio en su obra homónima9 ${ }^{9}$. El libro es la recopilación de una serie de artículos publicados en 1918. Pese a su antigüedad siguen vigentes sus argumentos a favor del matrimonio y sus denuncias en torno a las consecuencias personales y sociales del divorcio.

En síntesis, la superstición que ha creado la sociedad consumista, relativista y materialista consiste en atribuir al divorcio cualidades mágicas; el remedio infalible para todos los males personales, familiares y sociales. Si hoy como ayer es igualmente patético que muchos «sienten tan falso optimismo hacia el divorcio como cualquier romántico pudo sentirlo hacia el matrimonio», lo es más todavía que los medios de comunicación aticen el fuego de la superchería, de ese sentimentalismo rosado de aquel que imagina su historia con el final del cuento de hadas «---y, después de ser divorciados por papá gobierno, el príncipe y la princesa fueron felices por siempre y comieron perdices». La realidad cruda desmiente el cuento de hadas: Como cualquier observador puede testificar, el divorcio es un fracaso desde cualquier punto de vista. Incluso para quienes alucinan que es "el mal menor". Pero a quienes de buena o mala fe lo presentan como expresión de libertad, es necesario que

\footnotetext{
9 G. K. CHESTERTON. «La superstición del divorcio (The Superstition of Divorce, 1920)». En: Obras completas. Tomo I. Barcelona: Plaza \& Janés, 1967; 1676 pp., de la p. 871 a la p. 936. Trad. de Eduardo Toda Valcárcel. Nueva edición en Sevilla: Los Papeles del Sitio, 2008; 144 pp. Trad. de Aurora Rice Derqui. Prólogo de Enrique García Máiquez; ISBN 13: 978-84-935892-5-7.
} 
alguien, alguna vez, les muestre que, lejos de ser señal de libertad, el divorcio es una forma de autoengaño, de alucinógeno, de doble alienación -el alienado se resiste a aceptar que lo está-. En fin, el divorcio es esa superstición que los políticos quieren imponer a la sociedad pese a la realidad y al persistente fracaso con los que se enfrenta.

Para la gerencia de la superstición, la comunidad política tiene a la mano un glosario de calificativos que van desde "católico obsoleto", a "retrógrado", pasando por "medieval", "intolerante" y otros, y los dedican a quienes se pronuncien en contra del aborto, de las relaciones extraconyugales, de las píldoras abortivas o el sexo libre. Estos mismos adjetivos, y por las mismas sin-razones, son utilizados para identificar a quienes denuncian la falsedad de los dogmas sociales, y de la superstición que la sociedad de consumo ha elaborado para sostener que el divorcio soluciona algún problema conyugal, familiar o social.

Una breve digresión: Pese a que la indisolubilidad del matrimonio es asociado a la religión católica, los problemas, denuncias y cuestionamientos al divorcio no están enclaustrados en el ambiente religioso. Por el contrario, para el desarrollo del Derecho que defiende la vida y la dignidad del hombre, la familia y el matrimonio y para el desarrollo de la humanidad, ha sido decisivo que los juristas católicos reconozcan que la relación entre la razón y la naturaleza es la fuente de la que brota el manantial del Derecho; ha sido decisivo que hayan tomado distancia del derecho religioso, aquel que se construye a partir de la fe; y que se hayan puesto de parte de la filosofía. No obstante, si se revisa el pasado reciente del Derecho se advierte que en la formación de la Constitución histórica del Perú, y hasta la Declaración de los Derechos Humanos, después de la Segunda Guerra Mundial, la cuestión sobre los fundamentos de la legislación parecía clara. Pero, en el último medio siglo se dio un cambio dramático. La idea del derecho natural se considera hoy una doctrina católica más bien singular, sobre la que no vale la pena discutir fuera del ámbito católico, de modo que invocarlo sería casi una ingenuidad.

Otra arma con la que cuenta la defensa de la superstición es el Positivismo: Tal como se repite en el aula universitaria, la visión positivista del mundo es una de las grandes e irrenunciables expresiones de la creatividad humana; afirmando también que por ella misma, esta visión resulta insuficiente para el logro de la justicia y la paz. La razón positivista no es el todo del universo cultural humano, pues solo percibe aquello que es funcional. Por tanto, sería erróneo considerar que la razón positivista sea la única cultura válida, relegando todas las otras realidades culturales a la condición de subculturas; $\mathrm{o}$ al positivismo como único y exclusivo fundamento común para la formación 
del Derecho, mientras son preteridas todas las otras convicciones y los otros valores de la cultura.

Es necesario superar esa visión positivista para acercarse a la naturaleza en toda su profundidad y requerimientos; a la globalidad que no reconoce límites. El cruel asesinato de un universitario durante un partido de fútbol, en el interior de un estadio limeño; la misma existencia de la "barra brava" que lo asesinó, de sus organizaciones mentoras (públicas y privadas) y de la impunidad y otros privilegios de que gozan, son apenas reflejos pálidos de una realidad angustiosa: al iniciarse el s. XXI, el matrimonio y la familia sufren los embates de la prepotencia de la opinión pública manipulada, y de las arbitrariedades del poder. Matrimonio y familia están en peligro de extinción.

“Una concepción positivista de la naturaleza, que comprende la naturaleza en modo puramente funcional, como las ciencias naturales la explican, no puede crear ningún puente hacia el Ethos y el Derecho, sino suscitar nuevamente solo respuestas funcionales. Sin embargo, -continúa el Papa- lo mismo vale también para la razón en una visión positivista, que muchos consideran como la única visión científica. En ella, aquello que no es verificable o recusable no entra en el ámbito de la razón en sentido estricto. Por eso, el ethos y la religión se deben reducir al ámbito de lo subjetivo y caen fuera del ámbito de la razón en sentido estricto de la palabra. Donde rige el dominio exclusivo de la razón positivista -y este es en gran parte el caso de nuestra conciencia pública- las fuentes clásicas de conocimiento del ethos y del derecho quedan fuera de juego. Ésta es una situación dramática que interesa a todos y sobre la cual es necesaria una discusión pública..." ${ }^{10}$.

Pese a lo que se pregone en los medios o en la academia o en el Congreso, la doctrina de los Derechos Humanos implica la consciencia de la igualdad ante la ley, de la dignidad inviolable del ser humano y de la responsabilidad de los hombres por su conducta. Esta doctrina es el producto de la conjunción de las culturas griega, romana y judeo-cristiana. El pensamiento filosófico, la fe en Dios y el criterio jurídico. El hombre de Derecho (varón o mujer, legislador, abogado o magistrado $)^{11}$ tienen ante sí el desafío de defender esta doctrina. Sus herramientas básicas no son otras que "la razón abierta al lenguaje del ser, un corazón dócil a la Verdad y su voluntad para capacitarse para así

\footnotetext{
10 Benedicto XVI. Op. Cit.

11 Nota del autor: A lo largo de este trabajo, como ya se habrá advertido, el término "hombre" abarca el concepto de "ser humano", varón y mujer. Por razones de espacio se hará referencia a los sujetos utilizando el género masculino que incluirá tanto al de sexo masculino como al de sexo femenino.
} 
establecer un verdadero Derecho" como lo proclamó el Papa Benedicto XVI ante el Bundestag alemán ${ }^{12}$. Esa convocatoria es pertinente pues es a partir de esta doctrina que se plasman las normas legales que son materia del presente ensayo y que declaran que "... la defensa de la persona humana y el respeto de su dignidad son el fin supremo de la sociedad y del Estado"13.

En su discurso ante el Parlamento alemán (Mayo del 2011), el Papa Benedicto XVI, al abordar una definición del Derecho se pregunta “¿Cómo se reconoce lo que es justo? En la historia, los ordenamientos jurídicos han estado casi siempre motivados en modo religioso: sobre la base de una referencia a la voluntad divina, se decide aquello que es justo entre los hombres. Contrariamente a otras grandes religiones, el cristianismo nunca ha impuesto al Estado y a la sociedad un derecho revelado, un ordenamiento jurídico derivado de una revelación. En cambio, se ha referido a la naturaleza y a la razón como verdaderas fuentes del derecho, se ha referido a la armonía entre razón objetiva y subjetiva, una armonía que, sin embargo, presupone que ambas esferas estén fundadas en la Razón creadora de Dios"14. El éxito del político puede ser también una seducción y, de esta forma, abre la puerta a la mixtificación del derecho, a la destrucción de la justicia. "Quita el derecho y, entonces, ¿qué distingue el Estado de una gran banda de bandidos?", dijo en cierta ocasión San Agustín. La historia peruana, con excesiva frecuencia ha experimentado que estas palabras no son una mera quimera. Hemos experimentado cómo el poder se separó del derecho, se enfrentó contra el derecho; cómo se ha pisoteado el derecho, de manera que el Estado se convirtió en el instrumento para la destrucción del derecho; se transformó en una cuadrilla de bandidos muy bien organizada, que podía amenazar el mundo entero y empujarlo hasta el borde del abismo."

En el presente ensayo, se pretende interpretar, a la luz del Derecho Natural, el Derecho Internacional y la doctrina católica ${ }^{15}$, el caos social derivado de los ataques a la dignidad del hombre, la familia y el matrimonio; tal vez

\footnotetext{
12 http://www.romereports.com/palio/discurso-de-benedicto-xvi-en-el-parlamento-aleman-comoreconocer-que-es-justo-y-que-es-injusto-spanish-4955.html\#.TnuXWBMJNzY.facebook. Consultado el 31 de octubre del 2011, 11:05 horas.

13 Art. $1^{\circ}$ de la Constitución Política de 1993. Ver: Rubio CoRREA, Marcial. Para Conocer la Constitución Política del Perú de 1993. Segunda edición. Lima: Fondo Editorial PUCP, 2010, p. 21.

14 http://www.romereports.com/palio/discurso-de-benedicto-xvi-en-el-parlamento-aleman-comoreconocer-que-es-justo-y-que-es-injusto-spanish-4955.html\#.TnuXWBMJNzY.facebook. Consultado el 01 de noviembre del 2011, 16:37 horas.

15 Para este efecto se ha consultado: POnTIFICIO CONSEJO « Justicia Y PAZ » COMPENDio De La Doctrina SOCIAL DE LA IGLESIA http:/ / www.vatican.va/roman_curia/pontifical_councils/ justpeace/documents/ rc_pc_justpeace_doc_20060526_compendio-dott-soc_sp.html. Los textos entrecomillados en este ensayo corresponden al Compendio; salvo que se indique expresamente alguna otra fuente.
} 
como lo plantea Javier Hervada cuando sostiene que el concepto clave es el de lo justo o derecho en sentido realista; y con la angustia de la búsqueda de instrumentos para proteger al hombre "frente al peligro de ver menoscabada su dignidad y su libertad ante la prepotencia de las fuerzas sociales y las potenciales arbitrariedades del poder"16. También se propone hacerse eco de la exhortación de Benedicto XVI pronunciada en Brasil en el 2007: A ser hombres y mujeres libres y responsables; a respetarse en el matrimonio, también en el romance y en el noviazgo; a resistir con fortaleza a las insidias del mal que llevan a una vida disoluta, paradójicamente vacía, al hacer perder la libertad y la felicidad verdaderas.

\section{POLÍTICA FAMILIAR}

La familia es el eje del presente ensayo. En él se acoge el planeamiento que sostiene que, lejos de ser solo objeto de la acción política, la familia debe ser sujeto sine qua non de esta actividad, movilizándose para «procurar que las leyes y las instituciones del Estado no solo no ofendan, sino que sostengan y defiendan positivamente sus derechos y deberes naturales. En este sentido, las familias deben crecer en la conciencia de ser 'protagonistas' de la llamada "política familiar" y asumir la responsabilidad de transformar la sociedad».

Desde esta perspectiva, la familia se fundamenta en la libre voluntad de los cónyuges de unirse en matrimonio, respetando el significado y los valores propios de esta institución.

La institución matrimonial nace, también para la sociedad, «del acto humano por el cual los esposos se dan y se reciben mutuamente» y se funda sobre la misma naturaleza del amor conyugal que, en cuanto don total y exclusivo, de mujer a varón y viceversa, comporta un compromiso definitivo expresado con el consentimiento recíproco, irrevocable y público. Al margen de este consentimiento, el matrimonio sería nulo. Este compromiso pide que las relaciones entre los miembros de la familia estén marcadas también por el sentido de la justicia y el respeto de los recíprocos derechos y deberes.

Ningún poder puede abolir el derecho natural al matrimonio, ni modificar sus características, ni su finalidad. El matrimonio tiene características propias, originarias y permanentes. Aunque no siempre se trasluzca con la misma

\footnotetext{
16 HervadA, Javier. Introducción crítica al Derecho Natural. México D.F.: Editorial MiNos, S.A. de C.V., 1999.
} 
claridad, todas las culturas dan testimonio de la dignidad de la unión matrimonial a pesar de los numerosos cambios que han tenido lugar a lo largo de los siglos en las diferentes, culturas, estructuras sociales y actitudes espirituales.

La sociedad está atravesando otra era de confusión. Las raíces de tal confusión se hunden en la erosión de la familia y del matrimonio -tarea en que se ha embarcado la comunidad política. Un politizado Derecho Positivo muestra tercamente su incapacidad para el logro del bien común y, a la par, su inclinación a favorecer, su labilidad, para servir a intereses subalternos. En este campo, más que en otros, se hace evidente la responsabilidad política del legislador. Esta responsabilidad está sintetizada en las palabras de Benedicto XVI: "(Para el político) Su criterio último y la motivación para su trabajo como político no debe ser el éxito y mucho menos el beneficio material. La política debe ser un compromiso por la justicia y crear así las condiciones básicas para la paz"17.

Aún desde el punto de vista jurídico positivista, la relación matrimonial se fundamenta en una piedra angular natural; el fenómeno jurídico en general tiene un fundamento natural.

La familia, que como institución social es muchísimo más antigua que el cristianismo, sigue construyendo en el presente, redes de relaciones interpersonales, internas y externas; y no ha dejado de ser el presupuesto del matrimonio. Este es el currículum que la hace "primera e insustituible escuela de socialidad, ejemplo y estímulo para las relaciones comunitarias más amplias en un clima de respeto, justicia, diálogo y amor». La existencia de familias que, pese a los embates, viven con este espíritu pone al descubierto las carencias y contradicciones de una sociedad que tiende a privilegiar relaciones basadas principalmente, cuando no exclusivamente, en criterios de eficiencia y funcionalidad. Es sabido que hay lágrimas y tragedias en cada familia y matrimonio como las hay en todas las relaciones humanas, pero las más dolorosas son las que los hombres crean y a las que se obligan, ellos mismos, a aplaudir como si se tratara solo de una comedia insulsa sin mayores consecuencias. Pero, con su misma vida, los cónyuges están llamados a dar testimonio de vida, ser testigos y anunciadores de la solidaridad familiar, del apoyo mutuo, del sentido unívoco del matrimonio, que la sociedad actual

\footnotetext{
17 http://www.romereports.com/palio/discurso-de-benedicto-xvi-en-el-parlamento-aleman-comoreconocer-que-es-justo-y-que-es-injusto-spanish-4955.html\#.TnuXWBMJNzY.facebook. Consultado el 31 de octubre del 2011, 11:10:06 horas.
} 
reconoce cada vez con mayor dificultad, especialmente cuando el Estado acepta versiones antojadizas y relativistas del mismo fundamento natural de la institución matrimonial.

La íntima relación entre familia, sociedad y Estado «impone también que la sociedad cumpla su deber fundamental de respetar y promover la familia misma». Estado y sociedad están llamados a garantizar y favorecer la genuina identidad de la vida familiar y a combatir todo lo que la altera y daña, respetando la prioridad y "preeminencia» de la familia. Téngase en cuenta que la histriónica normativista pretende que la realidad jurídica sea un amasijo de normas revestidas de formas constitucionales. Pero el Derecho involucra una densa trama de relaciones sociales. Entre ellas, se identifica a aquellas que se refieren a los derechos que tiene el hombre: las relaciones jurídicas. Siguiendo la antigua lección del Derecho Romano: donde hay sociedad, hay derecho. Éste está diseñado y construido con la argamasa de la alteridad; es decir de las relaciones entre los seres humanos. El conjunto de relaciones jurídicas constituye la estructura primaria y fundamental de la realidad jurídica.

De lo expresado, se sigue que la política familiar está llamada a salvaguardar los valores de la familia, desde la promoción de la intimidad y la convivencia familiar, hasta el respeto de la vida naciente y la efectiva libertad de elección en la educación de los hijos. La sociedad y el Estado no pueden, por tanto, ni absorber ni sustituir, ni reducir la dimensión social de la familia; más bien deben honrarla, reconocerla, respetarla y promoverla según el principio de subsidiaridad.

El servicio de la sociedad a la familia se concreta en el reconocimiento, el respeto y la promoción de los derechos de la familia. Todo esto requiere la realización de auténticas y eficaces políticas familiares, con intervenciones precisas, capaces de hacer frente a las necesidades que derivan de los derechos de la familia como tal. En este sentido, es necesario como requisito previo, esencial e irrenunciable, el reconocimiento - lo cual comporta la tutela, la valoración y la promoción - de la identidad de la familia, sociedad natural fundada sobre el matrimonio. Este reconocimiento establece una neta línea de demarcación entre la familia, entendida correctamente, y las otras formas de convivencia, que - por su naturaleza - no pueden merecer ni el nombre ni la condición de familia.

En cuanto a política familiar, la historia del Derecho Peruano dará cuenta de la frivolidad y facilismo con los que el Estado ha establecido la procedencia 
de la demanda de divorcio que se fundamente en hecho propio (el abandono del hogar conyugal que perpetra el propio demandante); y que en un salto jurídico regresivo ha expedido la norma que promueve que los municipios y los Notarios reemplacen al Poder Judicial en la función jurisdiccional al encomendarles una nueva función: destruir el vínculo matrimonial por la vía del divorcio convencional: El divorcio al paso. Esta vez el pretexto es el de disminuir la carga procesal del Poder Judicial. El resultado será contribuir a lograr un sistema eficaz de destrucción de aquellas mismas instituciones que la Constitución reconoce "como institutos naturales y fundamentales de la sociedad." El estropicio es coronado con la promulgación de la Ley N 29227 y el Decreto Supremo No 009-2008-JUS.

El reconocimiento, por parte de las instituciones civiles y del Estado, de la prioridad de la familia sobre cualquier otra comunidad y sobre la misma realidad estatal, comporta superar las concepciones meramente individualistas y asumir la dimensión familiar como perspectiva cultural y política, irrenunciable en la consideración de las personas. Ello no se coloca como alternativa de los derechos que las personas poseen individualmente, sino más bien como su apoyo y tutela. Esta perspectiva hace posible elaborar criterios normativos para una solución correcta de los diversos problemas sociales, porque las personas no deben ser consideradas solo singularmente, sino también en relación a sus propios núcleos familiares, cuyos valores específicos y exigencias han de ser tenidos en cuenta.

"Servir al derecho y combatir el dominio de la injusticia es y sigue siendo el deber fundamental del político. En un momento histórico, en el cual el hombre ha adquirido un poder hasta ahora inimaginable, este deber se convierte en algo particularmente urgente. El hombre tiene la capacidad de destruir el mundo. Se puede manipular a sí mismo. Puede, por decirlo así, hacer seres humanos y privar de su humanidad a otros seres humanos que sean hombres" 18 .

La invocación que hace el Papa también está dirigida a los legisladores y líderes de opinión en los ámbitos de la política familiar desde que no es la ley ni la convención social; es el amor (en el sentido de amor/ágape de la filosofía clásica) la piedra fundamental de la familia y del matrimonio. Siendo imprescindible en la existencia humana, cuando se manifiesta en el don total de dos personas en su complementariedad, el amor no puede limitarse a emociones o sentimientos accidentales, y mucho menos a la mera expresión

${ }_{18}$ Benedicto XVI. Op. Cit. 
sexual. La historia ha demostrado que cualquier sociedad que tiende a relativizar y a banalizar la experiencia del amor y de la sexualidad, exalta los aspectos efímeros de la vida y oscurece los valores fundamentales.

La norma positiva debe tener en cuenta la propia enseñanza milenaria: «Corresponde a cada uno, varón y mujer, reconocer y aceptar su identidad sexual. La diferencia y la complementariedad físicas, morales y espirituales, están orientadas a los bienes del matrimonio y al desarrollo de la vida familiar. La armonía de la pareja humana y de la sociedad depende en parte de la manera en que son vividas entre los sexos la complementariedad, la necesidad y el apoyo mutuos». Esta perspectiva lleva a considerar necesaria la adecuación del Derecho Positivo a la ley natural, según la cual la identidad sexual es indiscutible, porque es la condición objetiva para formar la pareja matrimonial.

La trascendencia del amor conyugal exige la estabilidad de la relación matrimonial y su indisolubilidad. La falta de estos requisitos perjudica la relación de amor exclusiva y total, propia del vínculo matrimonial, trayendo consigo graves sufrimientos y efectos negativos para el tejido social, para los hijos e incluso para los propios cónyuges.

La política familiar así planteada reconoce estabilidad y la indisolubilidad de la unión matrimonial, que no deben quedar confiadas exclusivamente a la intención y al compromiso de los individuos: la responsabilidad en el cuidado y la promoción de la familia, como institución natural y fundamental, precisamente en consideración de sus aspectos vitales e irrenunciables, compete principalmente a toda la sociedad. La necesidad de conferir un carácter institucional al matrimonio, fundándolo sobre un acto público, social y jurídicamente reconocido, deriva de exigencias básicas de naturaleza social.

La introducción del divorcio en las legislaciones civiles ha alimentado una visión relativista de la unión conyugal y se ha manifestado ampliamente como una verdadera plaga social.

\section{HOJA DE RUTA}

El 8 de octubre de 1930, por Decreto Ley se concretó el establecimiento del divorcio en el Perú. A la fecha, ha transcurrido el lapso suficiente para contemplar sus efectos de destrucción sistemática de la institución familiar y de su incontenible escalada legislativa para promover el divorcio frívolo. 
Éste tiene como respuesta inmediata el matrimonio frívolo al que se llega sin un mínimo de preparación. Es obvio que el divorcio y el matrimonio frívolos exoneran al Estado y a la sociedad de su obligación de educar. Si bien en 1930 el divorcio era considerado un baldón propio de familias ricas, hoy ya se ha universalizado, generalmente a expensas de la parte más débil de la sociedad conyugal. Las estadísticas y el escenario son apocalípticos: Hay un gran ahorro fiscal a expensas de la educación y formación humanas; y un resultado que solo deja pérdida de la conciencia colectiva de valores, deberes y responsabilidades.

Por lo tanto, es también oportuno señalar algunos hitos para la construcción de una hoja de ruta para la defensa de la institución jurídica de la familia, del matrimonio y, por ende, de la sociedad humana en el s. XXI.

En líneas generales, frente a la desidia actual se plantea el activismo que, en síntesis debe incorporar:

La política familiar activa. Todos los implicados deben asumir la necesidad de realizar políticas activas a favor del matrimonio y la familia. Cada uno, anunciando, advirtiendo desde su propia almenara ${ }^{19}$, asumiendo este reto como una responsabilidad propia, decisiva y gigante denunciando que el matrimonio está devaluado socialmente y que la familia y el matrimonio están siendo amenazados con la extinción: Hay que promover el matrimonio y la familia en el hogar, en el aula, el foro, en la cátedra, en los medios, en el Congreso, en los estrados y resoluciones judiciales.

La defensa global de la familia y el matrimonio fustigando el divorcio: la defensa de la vida debe llevar aparejada la defensa del santuario de la familia cuyo epicentro es el matrimonio. Solo se abrirá camino haciendo una defensa global de ambas cuestiones, en los ámbitos y con las intensidades que corresponda. Y defender la familia es defender el matrimonio denunciando los males personales y sociales que acarrea el divorcio y sosteniendo simultáneamente la necesidad de acabar con él.

El matrimonio indisoluble. Impetrar a los poderes públicos que legislen la posibilidad de un matrimonio perpetuo reconocido así por el Derecho Civil. Es decir que hay que insistir, como otra acción posible y compatible con las anteriores, en promover el matrimonio civil indisoluble -aun cuando solo

\footnotetext{
${ }^{19}$ El término almenara puede referirse a: Almenara (del árabe al-manāra, "faro" < nār, "fuego"): fuego que se hacía en las atalayas o torres ópticas, como señal de aviso.
} 
sea opcional. Aun cuando -por lo que se refiere a su concordancia con la ley natural objetiva- no sea una solución ideal se puede exigir una doble regulación civil del matrimonio que permitiera, por un lado, el matrimonio temporal y disoluble (el vigente) y, por otro, un nuevo matrimonio indisoluble- con los efectos divergentes e irrevocables, correspondientes para cada uno de ellos.

En este marco general, corresponde un acercamiento más analítico a lo que podría ser una estrategia forense de política familiar -ante los insistentes ataques polifacéticos en contra de la familia, la paternidad y el matrimonioa ser implementada por magistrados y abogados. La estrategia consiste en recurrir a la aplicación de doctrina del control de convencionalidad a partir de sus nociones básicas, sus orígenes, su desarrollo actual, el objeto y contenido de este control y sus efectos. Esta doctrina enfatiza el control difuso de la convencionalidad, es decir, la facultad que ostentan los jueces nacionales para rechazar de plano la aplicación, a pedido de parte o de oficio, de las reglas de derecho interno de un país, cuando éstas son incompatibles con el espíritu o la letra de las normas y convenios internacionales en materia de Derechos Humanos ratificados por el país respectivo.

Aún los defensores del positivismo a ultranza tendrán que aceptar que esta facultad está reconocida en la Constitución Política, cuando establece en su Cuarta Disposición Final y Transitoria que "Las normas relativas a los derechos y a las libertades que la Constitución reconoce se interpretan (sic) de conformidad con la Declaración Universal de Derechos Humanos y con los tratados y acuerdos internacionales sobre las mismas materias ratificados por el Perú" 20 .

Mientras el control de constitucionalidad tiene por meta afianzar la supremacía de la Constitución, el control de convencionalidad tiene como objetivo consolidar la vigencia de las convenciones internacionales en materia de Derechos Humanos. Téngase en cuenta que el control de convencionalidad, no se limita a la defensa activa de la Declaración Universal de Derechos Humanos y del Pacto de San José de Costa Rica. Alcanza a cualquier Convención o Declaración en materia de Derechos Humanos; a todos los tratados y acuerdos internacionales sobre las mismas materias de los que es parte el Perú, en el presente o en el futuro. Pero no solo aquellas convenciones protocolarmente sancionadas, porque en el Capítulo

20 Rubio CorreA, Marcial. Para Conocer la Constitución Política del Perú de 1993. Segunda Edición. Lima: Fondo Editorial PUCP, 2010, p. 313. 
I - Derechos Fundamentales de la Persona, el Art. $3^{\circ}$ de la Constitución ${ }^{21}$ “... amplía el espectro de derechos que puede reclamar una persona con validez jurídica y constitucional: no solo son derechos constitucionales los expresamente establecidos en el texto, sino también todos aquellos otros que cumplen los requisitos establecidos". Así lo señala el Dr. Marcial Rubio Correa $^{22}$ en su ya citada obra.

Más aún, conforme a la interpretación de la Corte Interamericana de Derechos Humanos, la doctrina que es elaborada como producto del ejercicio del control de la convencionalidad, además de requerir que los tribunales nacionales rechacen la aplicación de las reglas internas opuestas al Pacto de San José de Costa Rica, también exige que las reglas internas se sometan a su jurisprudencia. En esta posición de vanguardia en la defensa de los Derechos Humanos, a través de sus sentencias, la Corte Interamericana está dando a su jurisprudencia el mismo valor que el que otorga a la letra del Pacto de San José de Costa Rica.

Es muy significativo que hasta el 2010, la Corte Interamericana se había referido en más de una docena de casos al control de convencionalidad puesto que Corte Interamericana por sí misma ya practicaba el control de convencionalidad al considerar inválidas las normas nacionales de derecho interno que se opusieran al Pacto de San José de Costa Rica. En este aspecto, se ha convertido en un hito importante el reclamo de los trabajadores cesados del Congreso de la República del Perú, que llevaron su caso a la Corte Interamericana de Derechos Humanos. En esta sentencia la Corte somete a evaluación el atributo de convencionalidad de las pertinentes normas internas peruanas sin excluir leyes, decretos, reglamentos, resoluciones ministeriales ni las normas constitucionales de este país.

Después de casi veinte años de vigencia de la Constitución Política de 1993, el núcleo básico de su artículo Cuarto viene siendo sistemáticamente violado por leyes, reglamentos, otras normas legislativas de menor nivel y por la jurisprudencia que vejan la familia, la paternidad y el matrimonio. A las puertas del vigésimo aniversario constitucional resulta obvio que el control de la constitucionalidad, tanto el difuso como el concentrado, ha fracasado

\footnotetext{
${ }^{21}$ El Art. $3^{\circ}$ de la Constitución reconoce que: "La enumeración de los derechos establecidos en este capítulo no excluye los demás que la Constitución garantiza, ni otros de naturaleza análoga o que se fundan en la dignidad del hombre, o en los principios de soberanía del pueblo, del Estado democrático de derecho y de la forma republicana de gobierno."

22 Rubio Correa, Marcial. Para Conocer La Constitución Política Del Perú De 1993. Segunda Edición. Lima: Fondo Editorial PUCP, 2010. Pág. 51.
} 
en este aspecto. No de otra manera se explica la vigencia impune de tales normas que, por lo demás, ya están produciendo efectos sociales, jurídicos y políticos apocalípticos.

Hecha la aclaración, se debe mencionar dos pactos internacionales de los que el Perú es parte y sus normas sobre Familia y Matrimonio son vinculantes en el territorio peruano. Ellos son:

1. La Convención Americana sobre Derechos Humanos suscrita en la conferencia especializada interamericana sobre derechos humanos ${ }^{23}$.

2. Pacto Internacional de Derechos Económicos, Sociales y Culturales. Adoptado y abierto a la firma, ratificación y adhesión por la Asamblea General en su resolución 2200 A (XXI), de 16 de diciembre de $1966^{24}$.

El control de la convencionalidad debe rectificar las ambigüedades de la Constitución y poner un alto a los ataques a la familia y al matrimonio que tienen como punto de partida tanto la desidia en la aplicación, como la

${ }^{23}$ La Convención Americana sobre Derechos Humanos suscrita en la conferencia especializada interamericana sobre derechos humanos Artículo 17. Protección a la Familia.

I. La familia es el elemento natural y fundamental de la sociedad y debe ser protegida por la sociedad y el Estado.

II. Se reconoce el derecho del hombre y la mujer a contraer matrimonio y a fundar una familia si tienen la edad y las condiciones requeridas para ello por las leyes internas, en la medida en que éstas no afecten al principio de no discriminación establecido en esta Convención.

III. El matrimonio no puede celebrarse sin el libre y pleno consentimiento de los contrayentes.

IV. Los Estados Partes deben tomar medidas apropiadas para asegurar la igualdad de derechos y la adecuada equivalencia de responsabilidades de los cónyuges en cuanto al matrimonio, durante el matrimonio y en caso de disolución del mismo. En caso de disolución, se adoptará disposiciones que aseguren la protección necesaria de los hijos, sobre la base única del interés y conveniencia de ellos.

$\mathrm{V}$. La ley debe reconocer iguales derechos tanto a los hijos nacidos fuera de matrimonio como a los nacidos dentro del mismo.

24 Pacto Internacional de Derechos Económicos, Sociales y Culturales. Adoptado y abierto a la firma, ratificación y adhesión por la Asamblea General en su resolución 2200 A (XXI), de 16 de diciembre de 1966. Artículo 10 Los Estados Partes en el presente Pacto reconocen que:

I. Se debe conceder a la familia, que es el elemento natural y fundamental de la sociedad, la más amplia protección y asistencia posibles, especialmente para su constitución y mientras sea responsable del cuidado y la educación de los hijos a su cargo. El matrimonio debe contraerse con el libre consentimiento de los futuros cónyuges.

II. Se debe conceder especial protección a las madres durante un período de tiempo razonable antes y después del parto. Durante dicho período, a las madres que trabajen se les debe conceder licencia con remuneración o con prestaciones adecuadas de seguridad social.

III. Se debe adoptar medidas especiales de protección y asistencia en favor de todos los niños y adolescentes, sin discriminación alguna por razón de filiación o cualquier otra condición. Debe protegerse a los niños y adolescentes contra la explotación económica y social. Su empleo en trabajos nocivos para su moral y salud, o en los cuales peligre su vida o se corra el riesgo de perjudicar su desarrollo normal, será sancionado por la ley. Los Estados deben establecer también límites de edad por debajo de los cuales quede prohibido y sancionado por la ley el empleo a sueldo de mano de obra infantil. 
infracción del artículo Cuarto de la Constitución Política de 1993. El control debe hacer volver la vista de los encargados de la política familiar a las fuentes naturales del Derecho de Familia.

\section{COLOFÓN}

Es necesario hacer otra digresión, ya que al adoptar políticas familiares se ha aludido a la necesidad de abreviar la carga procesal asumida por el Poder Judicial. La solución de otros problemas coyunturales o sistémicos no puede edificarse a costa de la destrucción de la familia y el matrimonio. Es emblemático el proceso de distorsión legislativa emprendido con el objeto de solucionar la pesada carga laboral del Poder Judicial otorgando facultades jurisdiccionales en el área de Derecho de Familia a notarios y a alcaldes. La carga laboral nueva, la retrasada y la pendiente en el Poder Judicial son reales y gigantescas. Un solo ejemplo al paso: Con los incentivos legislativos al divorcio frívolo, se ha logrado un embalse de más de 3 millones y medio de demandas pendientes de solución. Para el congresista menos alerta, el proyecto del Divorcio al Paso supuso una posible cosecha de 17 millones de votos para la re-elección jsin contar con los votos de los terceros que están a la espera del respectivo divorcio! ${ }^{25}$

En cuanto a las "razones" esgrimidas por los políticos hay que reiterar: El problema de la carga laboral de la administración de justicia no se resolverá convirtiendo en Jueces de Familia a alcaldes y notarios: Este problema reclama soluciones serias que deben partir de la autonomía presupuestal del Poder Judicial; pese a quienes menosprecian su importancia. Su presupuesto es inferior al 3\% del Presupuesto Nacional, y es fijado por los otros Poderes cuando debiera estarlo en la Constitución y administrado en forma independiente. Es, por supuesto, comparativamente inferior al 6\% de los estándares de países civilizados.

Es hora de dotar al Poder Judicial de un presupuesto acorde con su condición de salvaguarda de la legalidad, de la seguridad y la estabilidad jurídicas que lo califican como el Primer Poder del Estado. No se olvide que, sin estas condiciones, no habrá inversión, ni nuevos puestos de trabajo, ni desarrollo económico.

\footnotetext{
${ }^{25}$ Véase la Ley $N^{\circ} 29227$ de 16 de mayo del 2008, Ley que regula el procedimiento no contencioso de la separación convencional y divorcio ulterior en las municipalidades y notarías. Y su reglamento, aprobado por Decreto Supremo No 009-2008- JUS.
} 
No solo es el monto presupuestal. El Poder Judicial (PJ) no puede permanecer expuesto a la indiferencia o al castigo o a las represalias del sistema político. Es urgente plasmar en leyes las respectivas normas constitucionales y los discursos sobre independencia del Poder Judicial y su independencia económica. Y tiene que preverse sistemas para evitar que se incremente la carga judicial sin la dotación de recursos, ni estudio del impacto de soluciones legislativas electoreras, improvisadas o de coyuntura.

En una palabra, el problema planteado exige un sistema que demuestre inequívocamente que la independencia del Poder Judicial no es precisamente la que fijan los otros poderes del Estado, con sus propias y particulares pautas y corruptelas. Y como resulta obvio, ese problema no tiene relación con la existencia del divorcio. Ni se aproximará a ninguna solución con la difusión del divorcio frívolo.

Es innegable que el barniz cultural, ideológico e histórico da color a las formas que asumen las relaciones sociales que se desprenden de un dato natural. Pero las relaciones sociales siguen fundándose en la naturaleza. Y el divorcio es contrario al reconocimiento de la subjetividad y de la prioridad social de la familia. Es por ello que se sostiene enfáticamente que la promoción legislativa y social del divorcio en general y del divorcio frívolo en específico ("divorcio al paso", "divorcio express", "divorcio delivery") es un poderoso estímulo para el matrimonio frívolo; promoción que es negativa para los fines de la construcción de una relación correcta y constructiva entre la familia, el Estado y la sociedad. 